\title{
EFFECT OF BOND COAT AND SUBSTRATE CHEMISTRY ON THE INTERFACIAL DEGRADATION OF THERMAL BARRIER COATINGS
}

\author{
L.T. Wu ${ }^{1}$, R.T. Wu ${ }^{1}$, T. Osada ${ }^{1}$, K.I. $\mathrm{Lee}^{2}$, M. Bai ${ }^{2}$, P. Xiao ${ }^{2}$ \\ ${ }^{1}$ National Institute for Materials Science, Tsukuba, 305-0047 Japan \\ ${ }^{2}$ School of Materials, The University of Manchester, Manchester M1 7HS, UK
}

Keywords: Thermal barrier coatings, Phase transformation, Interface

\begin{abstract}
Despite the benefit of increased operating temperature of turbine blades, the application of thermal barrier coatings (TBC) has brought the concern of coating spallation during jet engine operations. A significant portion of past research, was therefore, devoted to detailed analysis of the interfacial degradation behavior of TBC by numerical and analytical models. Nonetheless, these models tend to overlook the influence of the degradation on the complicated nature of substrate chemical diffusion/phase transformation. As a result, the predicted TBC lifetime expressed in terms of failure criterion (i.e. thermally grown oxide thickness) often deviate largely from that obtained by real experiment. The purpose of this research work is to clarify the role of substrate chemistry on the interfacial degradation of TBC. Extensive analysis was carried out on a set of systematically prepared commercial TBC subjected to different thermal exposure times. The results clearly indicated that the interfacial adhesion is a dynamic property, which depends on the substrate chemical diffusion/phase transformation. It became evident that the early spallation observed in several $\beta$ bond coat system was caused by two unique phase transformations. Furthermore, the phase transformation was shown to be closely associated with the inherent chemistry of the substrate.
\end{abstract}

\section{Introduction}

To cope with the ever-demanding operating conditions in modern jet engines, state-of-the art thermal barrier coatings based on yttriastabilized zirconia (YSZ) has been widely applied on top of the bulk Ni-based superalloy, to thermally protect the underlying alloy from approaching its melting temperature. Due to the porous columnar structure and high ionic diffusivity of YSZ in the ceramic top coat at high temperature, the ingress of oxygen can readily oxidize the underlying substrate, leading to catastrophic failure of the turbine structure. To address this issue, a platinum aluminide $(\mathrm{Ni}, \mathrm{Pt}) \mathrm{Al}$ bond coat, usually made by electrodeposition of a thin layer of platinum, following by a pack aluminization process, is applied between the ceramic top coat and the bulk superalloy. The bond coat is tailored with higher amount of $\mathrm{Al}$ content than the bulk alloy, which serves as a reservoir of $\mathrm{Al}$ to promote the preferential formation of a protective alumina as the thermally grown oxide (TGO) layer [1-3].

Despite the aforementioned protective measures, the TBC are still prone to spallation failure primarily driven by the interfacial rumpling of the bond coat during the course of high temperature oxidation and thermal cycling [4-7]. The general consensus for the cause of interfacial rumpling is thought to be the mismatch in the coefficient of thermal expansion between the multilayered structures of TBC [6,7]. Several studies have identified that the TGO growth kinetic plays an important role in the TBC lifetime, and that spallation is mainly attributed to the strain energy lying within the TGO $[8,9]$. However, many experimental investigations have shown that despite having faster TGO growth rate and more rumpling, certain bond coat and substrate pairs still outperformed others in terms of lifetime [10,11]. Despite considerable progress that has been made on modeling the interfacial evolution of TBC in terms of the stress state and the degree of rumpling, there has been a lack of understanding on how these values could be influenced by the chemical diffusion and phase transformation of bond coat and substrate during thermal cycling $[6,7,12,13]$.

In recent years, additional studies have been dedicated to the study of the effect of bond coat and substrate compositions on the degradation of TBC [14-18]. A previous study by the authors [18] identified the rate of $\beta$ to $\gamma^{\prime}$ transformation driven by Al depletion as a dominant factor in degrading the interfacial adhesion of the TBC samples studied (Fig. 1). It was speculated that the $\gamma^{\prime}$ formation containing highly concentrated $\mathrm{Ti}$ near the bond coat/TGO interface may weaken the interface by forming $\mathrm{TiO}_{2}$. However, preliminary analysis by electron probe microscope Analysis (EPMA) indicated that while traces of $\mathrm{TiO}_{2}$ was present in the TGO layer of the SRR99 LT Pt-Al specimen, the same phenomenon could not be observed on the TMS-82+ HT Pt-Al specimen (details on the designation of these TBC systems are given in the Experimental section), which also had similar Ti enrichment and poor interfacial adhesion after $\gamma^{\prime}$ formation near the bond coat/TGO interface (see Figure 2). This implies that the formation of the less adhesive oxide cannot be the only mechanism causing the interfacial degradation of TBC. 

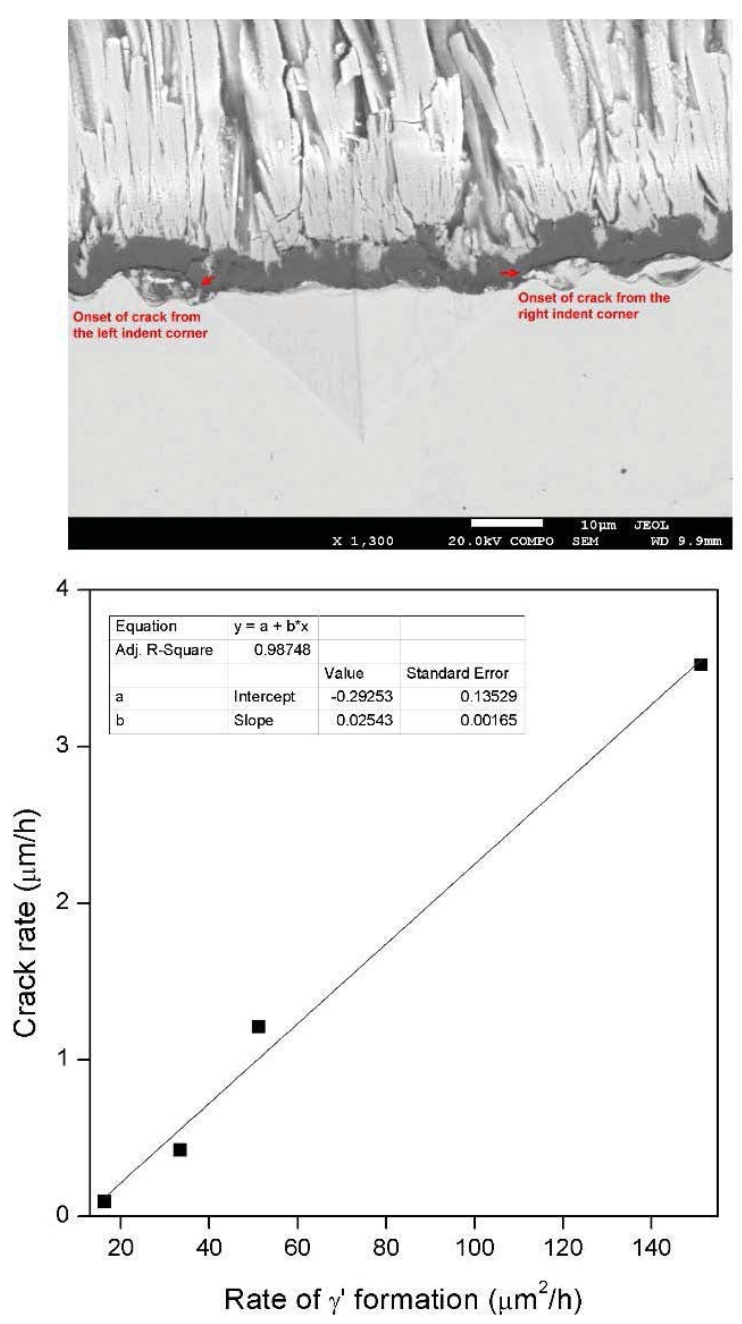

Fig. 1. Previous results indicating a linear dependency of the interfacial adhesion on the rate of $\gamma^{\prime}$ formation [18].

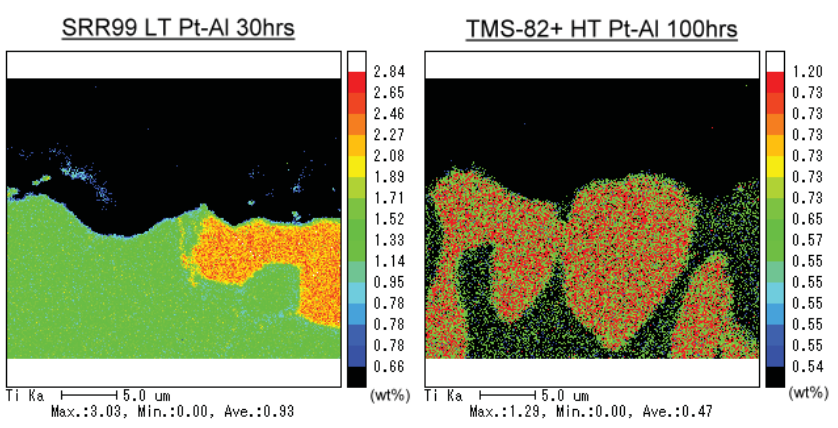

Fig. 2. EPMA mapping showing the formation of Ti enriched $\gamma^{\prime}$ in the bond coat region near the oxide-bond interface of the SRR99 LT Pt-Al (containing traces of $\mathrm{TiO}_{2}$ in the TGO) and TMS-82+ HT $\mathrm{Pt}-\mathrm{Al}$ after 30 and $100 \mathrm{~h}$ of isothermal exposure, respectively.

The current study seeks to clarify the difference in the degradation mechanisms between the SRR99 LT Pt-Al and TMS-82+ HT Pt-Al specimens, utilizing a systematic approach similar to the previous work [18].The results have clearly indicated that the TBC interfaces may degrade not only by the formation of less adhesive oxides (i.e. $\mathrm{TiO}_{2}$ or Spinels), but also due to the misfit stress induced in the TGO layer resulting from the martensitic transformation induced strain and thermomechanical mismatch between the different phases during cooling. Moreover, the results here have clearly demonstrated the previously proposed concept that the TBC spallation life is dependent on the dynamic variation of both the driving force for spallation and interfacial fracture toughness [18].

\section{Experimental details}

Three industrial standard single-crystal nickel based superalloys were used in this work: CMSX-4, SRR99, and TMS-82+. The nominal compositions for these alloys are listed in Table I. Three diffusional bond coats: HT Pt-Al, LT Pt-Al and Pt-diffusion (where HT implies high temperature low aluminum activity, LT implies low temperature high aluminum activity, and Pt-diffusion refers to platinum diffused without aluminisation), were deposited onto the aforementioned superalloys. Lastly, yttria stabilized zirconia top coats of approximately $175 \mu \mathrm{m}$ thickness were deposited onto the bond coats using electron beam physical vapor deposition. The detailed material processing can be found in a separate work [18]. In total, five unique TBC systems were prepared for this study (Table II).

Table I. Nominal Compostion of the three superalloys used in this work ( $\mathrm{wt} \%)$

\begin{tabular}{|c|c|c|c|c|c|c|}
\hline Substrate & Co & Cr & Mo & W & Al & Ti \\
\hline SRR99 & 5.0 & 8.0 & - & 9.5 & 5.5 & 2.2 \\
\hline TMS-82+ & 7.8 & 4.9 & 1.9 & 8.7 & 5.3 & 0.5 \\
\hline CMSX-4 & 9.6 & 6.5 & 0.6 & 6.4 & 5.6 & 1.0 \\
\hline & Ta & Hf & Re & Ru & C & Ni \\
\hline \multicolumn{1}{|c|}{ SRR99 } & 2.8 & - & - & - & - & Bal. \\
\hline TMS-82+ & 6.0 & 0.1 & 2.4 & - & - & Bal. \\
\hline CMSX-4 & 6.5 & 0.1 & 3.0 & - & - & Bal. \\
\hline
\end{tabular}

Table II. Visual representation of the five TBC systems used in this work

\begin{tabular}{|c|c|c|c|}
\hline & \multicolumn{3}{|c|}{ SUPERALLOY SUBSTRATE } \\
\hline BOND COAT & CMSX-4 & TMS-82+ & SRR99 \\
\hline HT Pt-Al & & $\boldsymbol{V}$ & \\
\hline LT Pt-Al & $\boldsymbol{V}$ & $\boldsymbol{\checkmark}$ & $\boldsymbol{}$ \\
\hline Pt diffusion & & $\boldsymbol{r}$ & \\
\hline
\end{tabular}

The as-prepared TBC systems were subjected to isothermal exposures at a furnace temperature of $1135^{\circ} \mathrm{C}$ for $0,30,50,100 \mathrm{~h}$. Subsequently, microstructural characterizations (both $\mathrm{OM}$ and SEM) were conducted to record the interfacial evolution of the TBC with isothermal exposure times. Micrographs across the entire $\mathrm{TGO} /$ bond coat interfacial area were taken for every specimen. EPMA (Electron Probe Microscope Analysis) scan was carried out at the TGO/bond coat interfacial area of all the thermally exposed specimens. A beam current of $20 \mathrm{nA}$ was applied with a beam size of about $1 \mu \mathrm{m}$, at an accelerating voltage of $15 \mathrm{kV}$. The scans were done at a step size of $0.1 \mu \mathrm{m}$ in both $\mathrm{X}$ and $\mathrm{Y}$ directions for an area of $30.00 \times 25.00 \mu \mathrm{m}^{2}$.

A JEOL FE-SEM equipped with EBSD detector and OIM data collection software was used to carry out the phase and grain orientation analysis near the bond coat/TGO interfacial region of the 0,30 , and $100 \mathrm{~h}$ specimens. The scans were done at a step size between 0.4 to $0.6 \mu \mathrm{m}$ in both $\mathrm{X}$ and $\mathrm{Y}$ directions, for an area of $28.000 \times 25.000 \mu \mathrm{m}^{2}$. For specimens that had inherently large 
grains, an additional scan was conducted using the same step size and area settings as before.

To conduct a thermodynamic simulation on the TBC using the Thermo-Calc software, energy-dispersive X-ray spectroscopy (EDX) was utilized to determine the major alloying compositions near the oxide-bond coat interface of the $100 \mathrm{~h}$ isothermally exposed CMSX-4 LT Pt-Al and the $50 \mathrm{~h}$ isothermally exposed TMS-82+ LT Pt-Al specimens. A total of 23 point scans were conducted at locations approximately $1-3 \mu \mathrm{m}$ below the TGO/bond coat interface on both specimens in order to avoid collecting secondary electron signals from the TGO layer (i.e. oxygen and aluminum). Average values of the alloying elements in $\mathrm{wt} \%$ were obtained and used in the Thermo-Calc simulation.

\section{Results}

\section{$\underline{\text { 3.1 Microscopic observation near the } \mathrm{TGO} / \text { bond coat interface }}$}

A comparison of the bond coat regions between the SRR99 and CMSX-4 LT Pt-Al systems after 30 and $50 \mathrm{~h}$ isothermal exposures is shown in Figure 3. It can be seen that the phase morphology differs significantly between the two alloys. The SRR99 LT Pt-Al specimen exhibited short circuit diffusion along the grain boundaries of $\beta$ grains, where $\gamma^{\prime}$ phase was precipitated after isothermally exposed for $30 \mathrm{~h}$. In addition, large $\gamma^{\prime}$ precipitates were also observed near the TGO/bond coat interfacial region. The $30 \mathrm{~h}$ isothermally exposed CMSX-4 LT Pt-Al specimen, on the other hand, maintained a uniform layer of $\beta$ phase without the presence of $\gamma^{\prime}$ precipitates. After $50 \mathrm{~h}$ of isothermal exposure, TGO spallation had already occurred on the SRR99 LT Pt-Al specimen, whereas the TGO layer of the CMSX-4 LT Pt-Al specimen remained well intact. In addition, CMSX-4 LT Pt-Al was found to contain the martensitic phase (lath structures) along with $\beta$ phase.
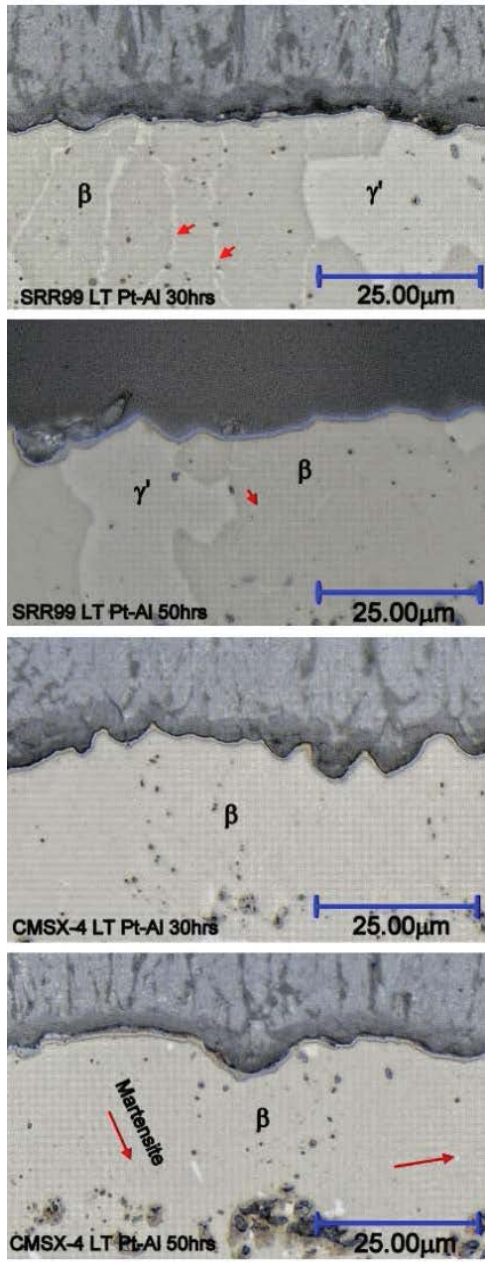

Fig. 3. SEM micrographs showing a comparison of bond coat regions between 30 and $50 \mathrm{~h}$ isothermally exposed SRR99 LT Pt$\mathrm{Al}$ and CMSX-4 LT Pt-Al specimens, with a unique $\gamma^{\prime}$ formation at the grain boundaries of the SRR99 specimen.

Similarly, Figure 4 shows a comparison of the bond coat regions between the TMS-82+ HT Pt-Al and LT Pt-Al systems after 30 and $50 \mathrm{~h}$ isothermal exposures. Again, the phase distribution differs significantly between these two bond coats. The TMS-82+ HT PtAl specimen was found to contain a uniform distribution of martensitic phase (coarse lath structures); whereas the TMS-82+ LT Pt-Al specimen maintained mostly $\beta$ phase with minimal formation of martensites and $\gamma^{\prime}$ precipitates after $30 \mathrm{~h}$ of isothermal expsoure. For the $50 \mathrm{~h}$ isothermal exposed specimens, large particles of $\gamma^{\prime}$ precipitates appeared on the TMS-82+ HT Pt-Al specimen alongside martensitic phase. The TMS-82+ LT-Pt-Al, on the other hand, began to show a larger distribution of martensites and some $\gamma^{\prime}$ precipitates beside the $\beta$ phase. 

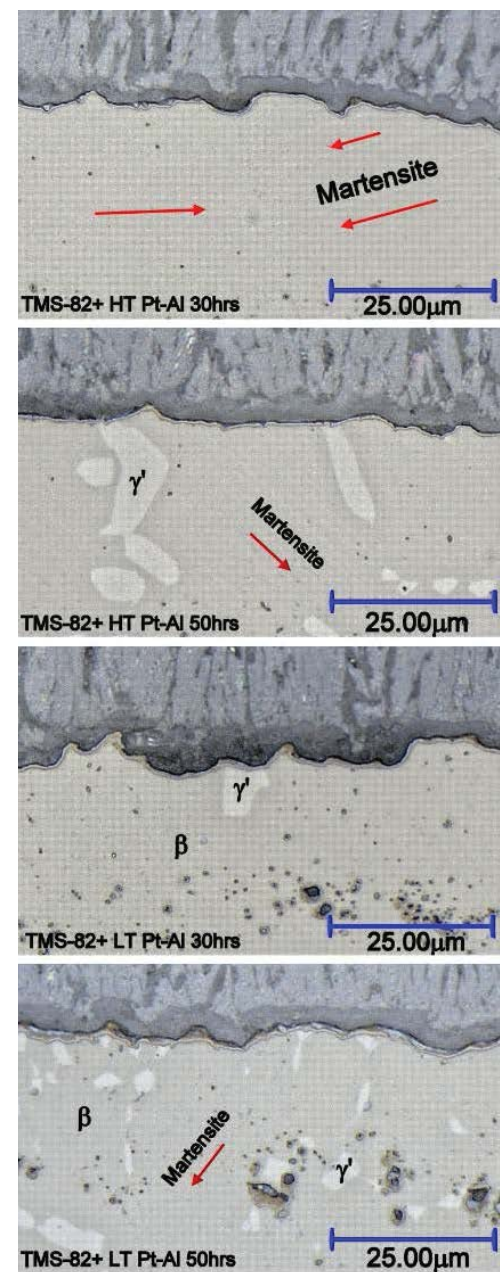

Fig. 4. SEM micrographs showing a comparison of bond coat regions between 30 and $50 \mathrm{~h}$ isothermally exposed TMS-82+ HT Pt-Al and TMS-82+ LT Pt-Al specimens, with a complete martensitic transformation in the HT-Pt-Al bond coat.

\subsection{EBSD mapping analyses near the TGO/bond coat interface}

The unique features in the bond coat morphology and phase distribution of the TMS-82+ HT Pt-Al and SRR99 LT Pt-Al specimens are further highlighted in this section by EBSD mapping. It should be noted here that the EBSD pattern of the TGO layer could not be accurately indexed (most likely due to its large residual stress induced crystal distortion), and hence, was purposefully removed from all maps for the ease of viewing. In addition, the inverse pole figures of all the EBSD maps in this study refer only to the bond coat (note the top coat had been excluded as shown in grayscale). Figure 5 shows a comparison of the grain morphology between the TMS-82+ HT Pt-Al and LT Pt-Al specimens in the as coated condition. Prior to isothermal exposure, the TMS-82+ HT $\mathrm{Pt}-\mathrm{Al}$ specimen was found to contain much larger grains than the TMS-82+ LT Pt-Al bond coat.

After $30 \mathrm{~h}$ of isothermal exposure, the TMS-82+ HT Pt-Al bond coat transformed completely from the as coated $\beta$ phase to an acicular martensitic phase, while the TMS-82+ LT Pt-Al specimen kept mostly its $\beta$ phase with enlarged grain size (Figure 6). Significant degradation can be seen in the pattern quality of the 30 $\mathrm{h}$ isothermally exposed TMS-82+ HT Pt-Al, which is most likely due to lattice distortion associated with the significant martensitic phase transformation.

Figure 7 provides a comparison of the phase distribution between the SRR99 LT Pt-Al and CMSX-4 LT Pt-Al specimens after $30 \mathrm{~h}$ isothermal exposure. The SRR99 LT Pt-Al specimen was found to exhibit the formation of $\gamma^{\prime}$ phase at the grain boundary and within the matrix of $\beta$ phase as secondary phase. The CMSX-4 LT Pt-Al map, on the other hand, showed very uniform grains of clean $\beta$ phase.

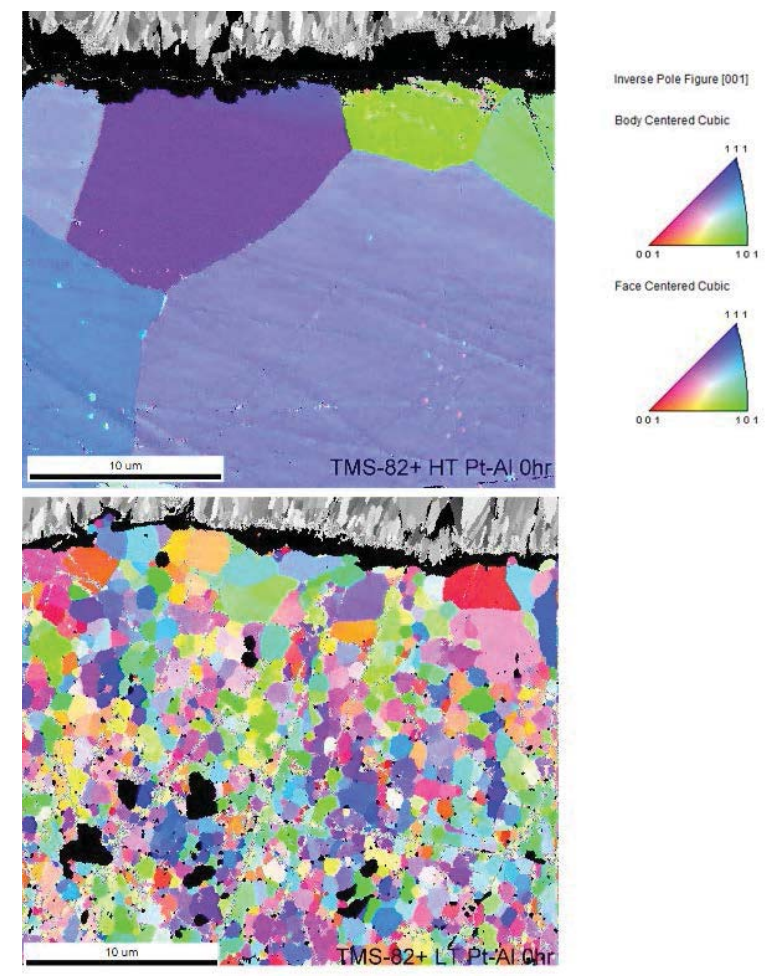

Fig. 5. EBSD mapping showing a comparison of grain morphology of the bond coat region near the oxide-bond interface of the TMS82+ HT Pt-Al and TMS-82+ LT Pt-Al prior to isothermal exposure, with the HT Pt-Al bond coat having much larger grains. 


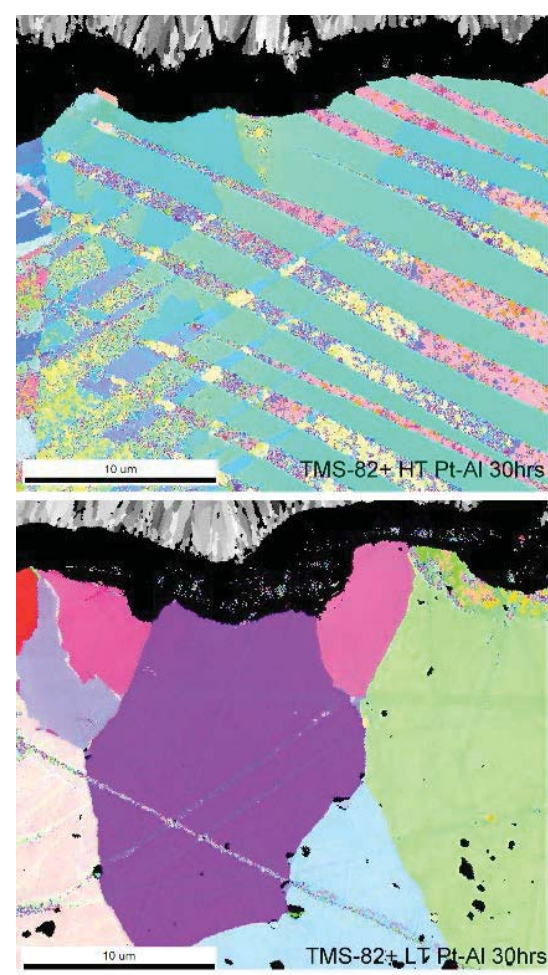

Inverse Pote Figure 1001

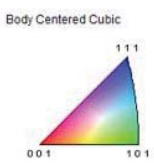

Face Centered Cubic

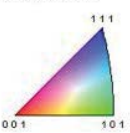

Fig. 6. EBSD mapping showing the lath martensitic structure of the TMS- $82+$ HT Pt-Al specimen, in contrast to the $\beta$ phase of the TMS-82+ LT Pt-Al after $30 \mathrm{~h}$ of isothermal exposure.
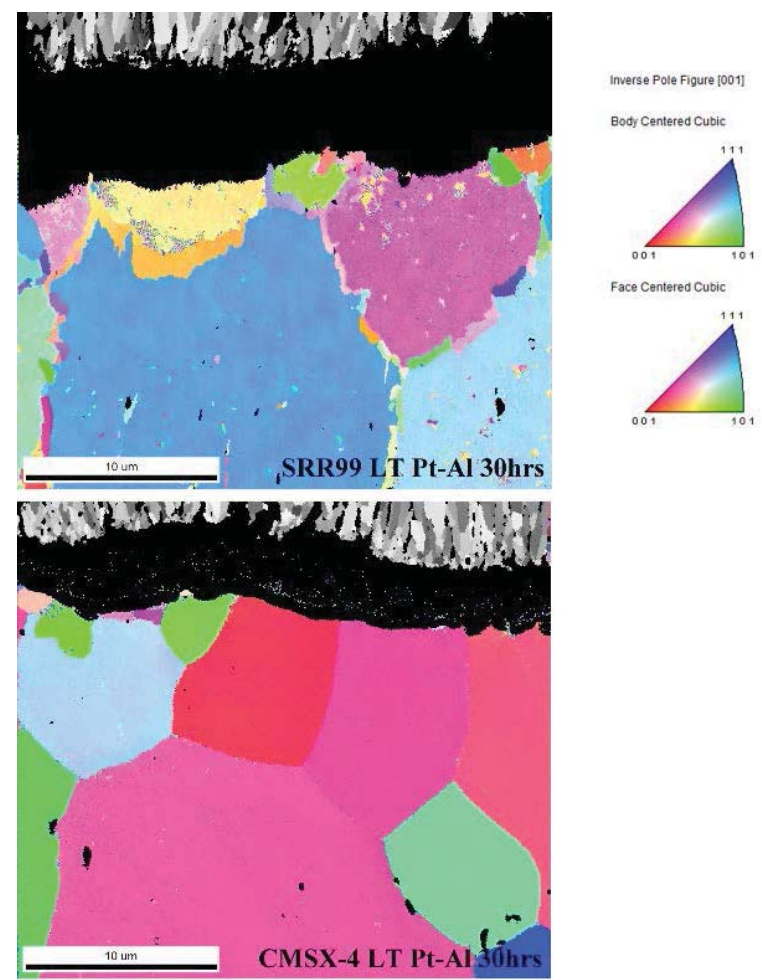

Fig. 7. EBSD mapping showing the unique $\gamma^{\prime}$ precipitation at the grain boundaries of the SRR LT Pt-Al, in contrast to the clean and uniform $\beta$ phase of the CMSX-4 LT Pt-Al specimen after $30 \mathrm{~h}$ of isothermal exposure.
Figure 8 shows a comparison between the phase distribution of CMSX-4 LT Pt-Al, TMS-82+ LT Pt-Al and TMS-82+ HT Pt-Al after $100 \mathrm{~h}$ of isothermal exposure. The CMSX-4 LT Pt-Al specimen underwent a transformation from $\beta$ phase to mostly coarse martensitic structure together with minor amount of $\gamma^{\prime}$ phase. The TMS-82+ LT Pt-Al specimen, on the other hand, showed the presence of more $\gamma^{\prime}$ phase along with a coarse martensitic structure. The Kikuchi pattern of the martensitic region in the TMS-82+ LT $\mathrm{Pt}-\mathrm{Al}$ specimen is relatively unclear in comparison with the CMSX4 specimen. Lastly, the formation of much larger $\gamma^{\prime}$ grains could be found in the TMS-82+ HT Pt-Al specimen with patterns of martensitic regions below recognition.
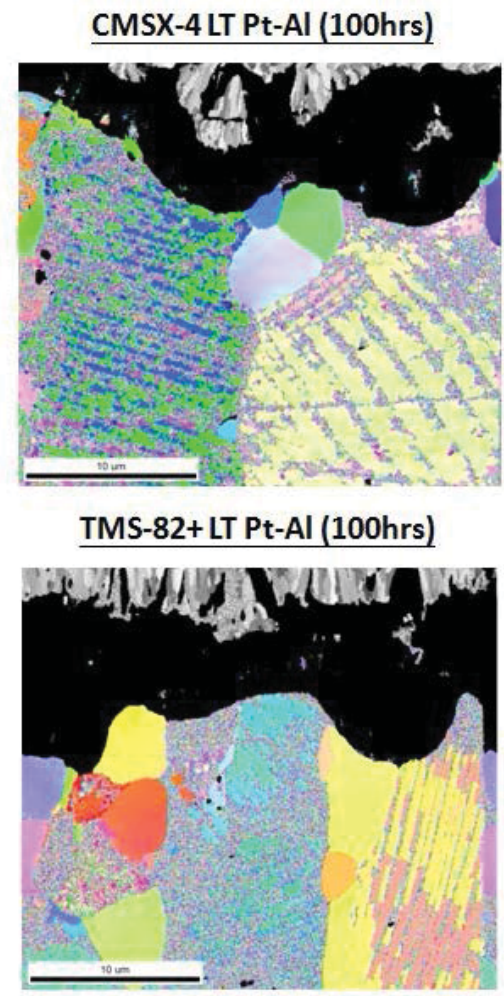

TMS-82+ HT Pt-Al (100hrs)

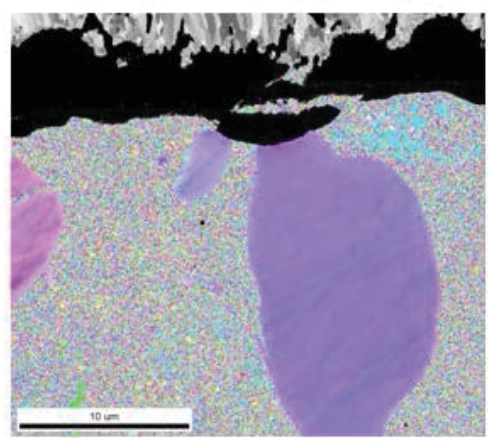

Fig. 8. EBSD mapping showing a comparison of the extent of Kikuchi patent degradation of three TBC after $100 \mathrm{~h}$ isothermal exposure.

Figure 9 compares the phase and microstructure morphology between the $100 \mathrm{~h}$ isothermally exposed TMS-82+ Pt-diffusion and the $30 \mathrm{~h}$ isothermally exposed SRR99 LT Pt-Al, which highlights the inherent difference between the $\gamma$ and $\gamma^{\prime}$ structure of the Pt- 
diffusion bond coat and the $\beta$ structure of the LT Pt-Al bond coat. It can be seen that the TMS-82+ Pt-diffusion specimen consisted of small grains of more or less uniform sizes, whereas, the SRR99 LT Pt-Al specimen contained much larger $\beta$ grains with $\gamma^{\prime}$ precipitates of various sizes.

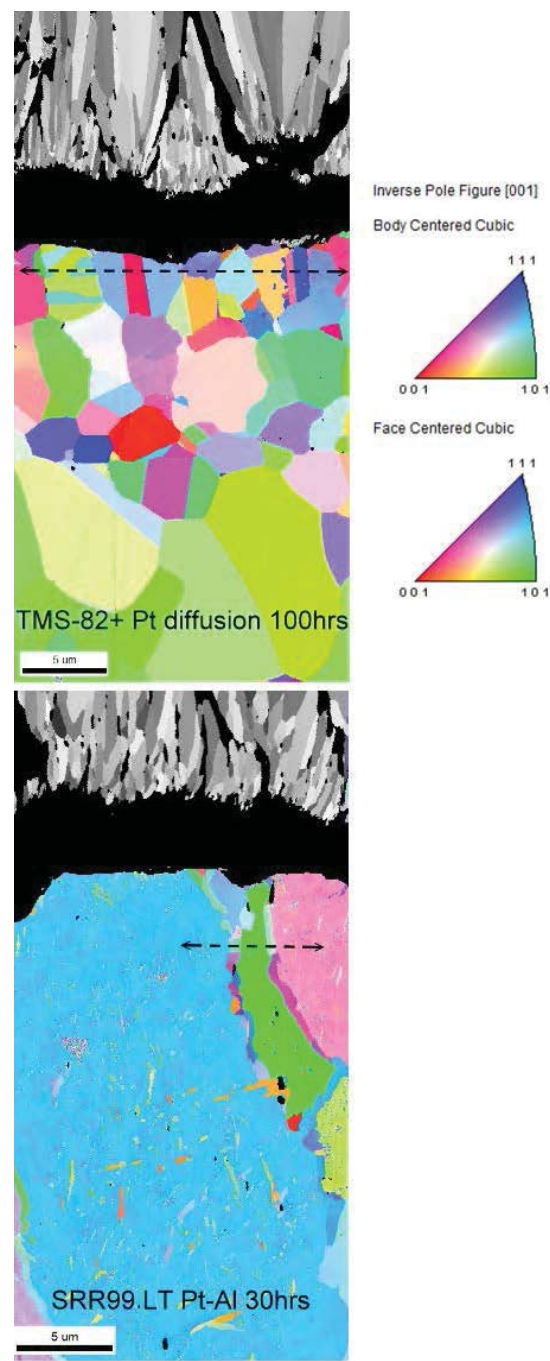

Fig. 9. EBSD mapping highlighting the inherent difference between the $\gamma+\gamma^{\prime}$ microstrucuture of the Pt-diffusion bond coat and the $\beta$ microstructure of the LT Pt-Al bond coat.

\section{$\underline{3.3 \text { EPMA mapping analysis near TGO/bond coat regions }}$}

EPMA analysis was carried out to study the chemical diffusion and segregation behavior of the $30 \mathrm{~h}$ and $100 \mathrm{~h}$ isothermally exposed TMS-82+ Pt-diffusion bond coat (see Figure 10). After $30 \mathrm{~h}$ of isothermal exposure, the $\mathrm{Al}$ content near the $\mathrm{TGO} /$ bond coat interface of the TMS-82+ Pt-diffusion specimen was uniformly depleted with corresponding enrichment in the $\mathrm{Cr}$ content. The $\mathrm{Ti}$ content was found to segregate below the $\mathrm{Cr}$ enriched layer at the exact location where $\mathrm{Cr}$ depletion occurred. It can be seen that the overall chemistry of the $\mathrm{Ti}$ and $\mathrm{Cr}$ segregation after $100 \mathrm{~h}$ of isothermal exposure remained very similar to that of the $30 \mathrm{~h}$, while further $\mathrm{Al}$ depletion took place. Traces of chromium oxide can be found in the TGO layer for both exposure times.
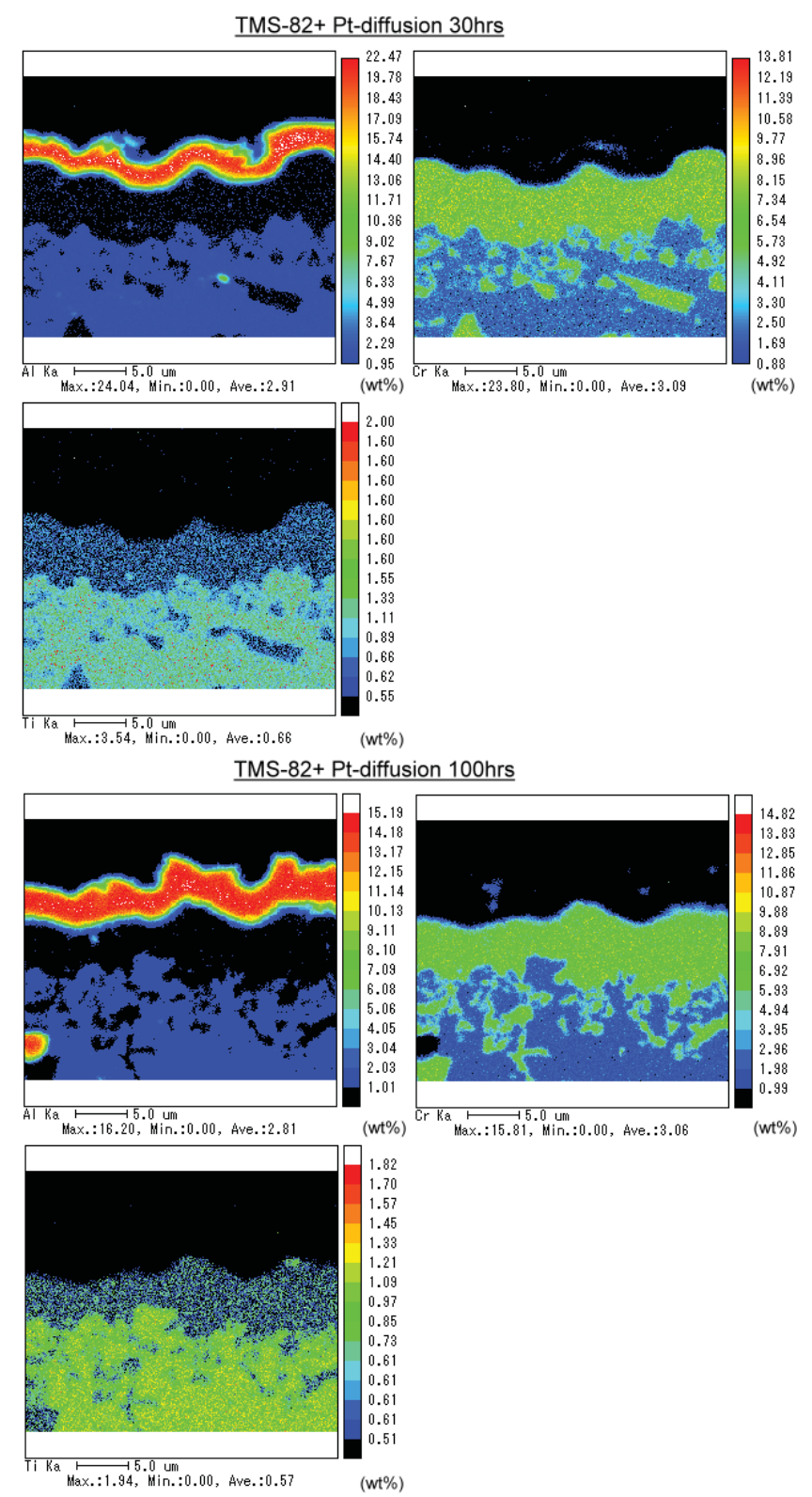

Fig. 10. EPMA mapping showing the chemistry near the oxidebond coat regions of the TMS- $82+$ Pt-diffusion specimens after 30 and $100 \mathrm{~h}$ of isothermal exposure, with uniformly depleted layer of $\mathrm{Al}$ and $\mathrm{Ti}$ while enriched with $\mathrm{Cr}$.

Figure 11 provides a direct comparison of the $\mathrm{Ti}$ and $\mathrm{Cr}$ distribution between the TMS-82+ LT Pt-Al and the CMSX-4 LT Pt-Al specimens after $100 \mathrm{~h}$ of isothermal exposure. Similarly, Ti-Cr segregation was found in the TMS-82+ LT Pt-Al specimen, except that the segregation occurred in small patches along bond coat region near the $\mathrm{TGO} /$ bond coat interface rather than layers as in the previous case. On the other hand, the CMSX-4 LT Pt-Al specimen showed a rather consistent $\mathrm{Cr}$ distribution with much less Ti content near the interface. Chromium oxide was detected in the TGO layers of both specimens. 


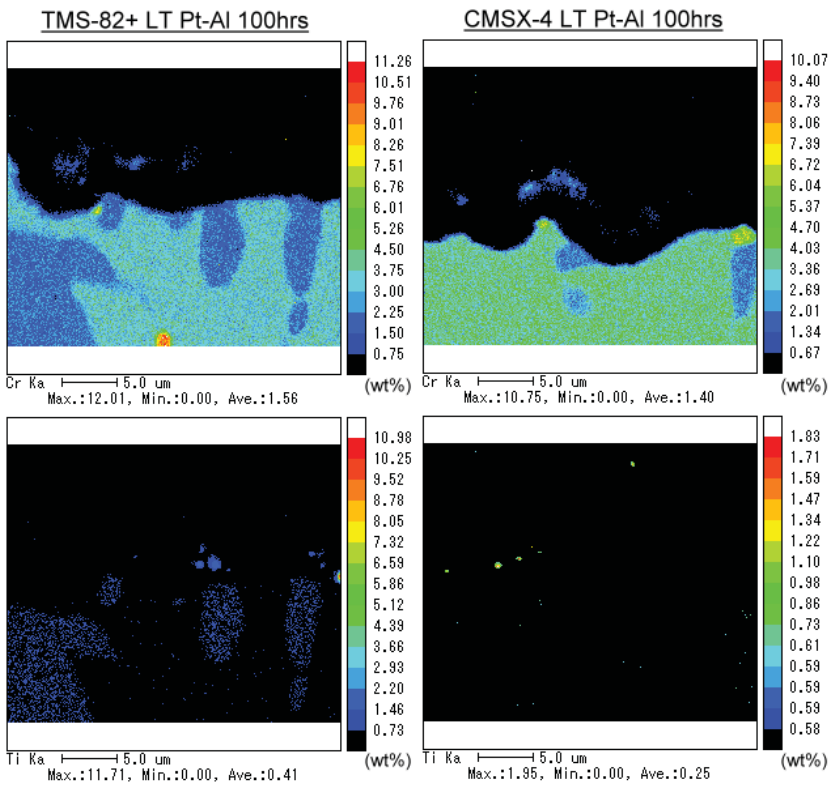

Fig. 11. EPMA mapping showing a comparison of $\mathrm{Cr}$ and $\mathrm{Ti}$ contents near oxide-bond coat interface between TMS-82+ LT Pt$\mathrm{Al}$ and CMSX-4 LT Pt-Al after $100 \mathrm{~h}$ of isothermal exposure, with CMSX-4 showing no obvious Ti presence.

\section{$\underline{3.4 \text { Simulation of phase transformation by Thermo-Calc }}$}

The Thermo-Calc software was used to clarify the effect of $\mathrm{Cr}$ content on the phase distribution of the LT Pt-Al bond coat system paired with the CMSX-4 alloy. A set of parameters including the isothermal temperature used $(1408 \mathrm{~K})$, and the bond coat compositions near the TGO/bond coat interface of the $100 \mathrm{~h}$ isothermally exposed CMSX-4 LT Pt-Al specimen were specified in the calculation. We assumed that the system is in a stable equilibrium state after certain amount of time. Note that the bond coat compositions were taken from the EDX analysis result as detailed in the experimental section (see Table III).

Table III. The nominal composition in wt. \% of the CMSX-4 LT Pt-Al and TMS-82+ LT Pt-Al bond coats as specified in the Thermo-Calc calculation

\begin{tabular}{|c|c|c|c|c|c|}
\hline Bond Coat & Co & Cr & Mo & W & $\mathrm{Al}$ \\
\hline $\begin{array}{c}\text { CMSX-4 } \\
\text { LT Pt-Al }\end{array}$ & 6.69 & 3.16 & 0.50 & 2.00 & 11.12 \\
\hline $\begin{array}{l}\text { TMS-82+ } \\
\text { LT Pt-Al }\end{array}$ & 4.90 & 2.89 & 0.48 & 1.86 & 11.79 \\
\hline & $\mathrm{Ti}$ & $\mathrm{Ta}$ & $\mathrm{Re}$ & $\mathrm{Pt}$ & $\mathrm{Ni}$ \\
\hline $\begin{array}{c}\text { CMSX-4 } \\
\text { LT Pt-Al }\end{array}$ & 0.010 & 5.35 & 0 & 20.43 & 50.21 \\
\hline $\begin{array}{c}\text { TMS-82+ } \\
\text { LT Pt-Al }\end{array}$ & 0.32 & 3.70 & 0 & 22.53 & 50.90 \\
\hline
\end{tabular}

Figure 12a is a plot of the mole-fraction of different phases near the $\mathrm{TGO} /$ bond coat interfaces of the $100 \mathrm{~h}$ isothermally exposed CMSX-4 LT Pt-Al alloy based on the calculation in Thermo-Calc as a function of $\mathrm{Cr}$ content. The results show an increase in the mole fraction of $\beta$ phase corresponding to a decrease in the $\gamma^{\prime}$ phase with increasing $\mathrm{Cr}$ content. The dotted line shows the relative distribution of the bond coat phases in the actual $100 \mathrm{~h}$ isothermally exposed CMSX-4 LT Pt-Al specimen. A similar analysis was carried out to study the effect of Ta content on the phase distribution of the $50 \mathrm{~h}$ isothermally exposed TMS-82+ LT Pt-Al. The purpose here is to see if an inherently low Ta content, such as in the case of the SRR99 LT Pt-Al specimen, could have an influence on the $\gamma^{\prime}$ transformation behavior. Again, the bond coat compositions used for Thermo-Calc analysis were taken from EDX line scans near the oxide-bond coat interface (see Table III). Thermo-Calc results given in Fig. $12 \mathrm{~b}$ also indicated an increase in the mole fraction of $\beta$ phase corresponding to a decrease in the $\gamma^{\prime}$ with increasing Ta content. However, the extent of the phase variation seemed much less in this case.
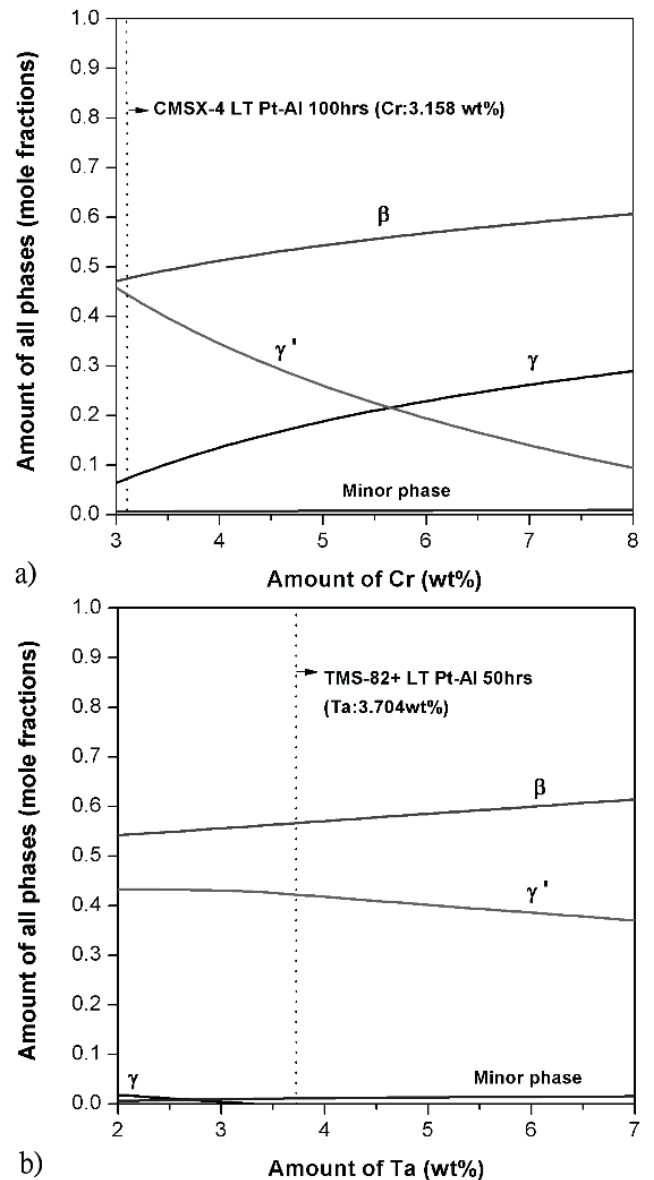

Fig. 12. The mole fraction of different phases existing near the $\mathrm{TGO} /$ bond coat interface of the bond coats in a) CMSX-4 LT Pt-Al $100 \mathrm{~h}$, and b) TMS-82+ LT Pt-Al $50 \mathrm{~h}$ specimens as a function of varying $\mathrm{Cr}$ and $\mathrm{Ta}$ contents, respectively. These elements generally help stabilizing $\beta$ phase.

\section{Discussion}

\section{$\underline{4.1 \text { Interfacial evolution during thermal exposure }}$}

The results reported in previous sections gave detailed information regarding phase evolution with thermal history, which provide insights into the degradation mechanism of TBC and offer clues on the cause of early spallation. Table IV is a summary of the phase evolution of the TBC, and their corresponding TGO stress obtained from the previous work [18] using the photo-luminescence piezospectroscopy and the R2 peak shift estimation. The phase constituents of the bond coat seem to have a huge influence on the 
TGO stress level. The TMS-82+ Pt-diffusion specimen with its $\gamma+$ $\gamma^{\prime}$ composition was measured to have the highest TGO stress. The CMSX-4 LT Pt-Al specimen having pure $\beta$ phase after $30 \mathrm{~h}$ of isothermal exposure had a slightly lower TGO stress than that of the TMS-82+ HT Pt-Al with all martensitic structure at $30 \mathrm{~h}(\sim 2.29$ GPa vs. $2.45 \mathrm{GPa}$ ). It should be noted here that the martensitic transformation is known to undergo molar volume shrinkage during cooling, and mostly likely, creates additional stress on the TGO layer (more on this will be discussed in Section 4.3).

Table IV. A summary of the phase evolution and TGO stress of all the bond coats studied between 30 and $100 \mathrm{~h}$ of thermal exposure [18]

\begin{tabular}{|c|c|c|c|}
\hline & \multicolumn{3}{|c|}{$\begin{array}{l}\text { Phase evolution and TGO stress during thermal } \\
\text { exposure }\end{array}$} \\
\hline & $30 \mathrm{~h}$ & $50 \mathrm{~h}$ & $100 \mathrm{~h}$ \\
\hline $\begin{array}{l}\text { SRR99 LT } \\
\text { Pt-Al }\end{array}$ & $\begin{array}{l}\gamma^{\prime} \\
\text { precipitates } \\
\text { (g.b. and } \\
\text { near } \\
\text { interface) }+\beta \\
\text { Stress: } \\
\text { 0.24GPa }\end{array}$ & -N/A (Spalled) & $\begin{array}{l}\text {-N/A } \\
\text { (Spalled) }\end{array}$ \\
\hline $\begin{array}{l}\text { TMS-82+ } \\
\text { HT Pt-Al }\end{array}$ & $\begin{array}{l}\text { All lath } \\
\text { martensitic } \\
\text { structure } \\
\text { Stress: } \\
\mathbf{2 . 4 5 G P a} \\
\end{array}$ & $\begin{array}{l}\text { Martensitic }+ \\
\gamma^{\prime} \text { (significant) } \\
\text { Stress: } \\
\text { 2.33GPa }\end{array}$ & $\begin{array}{l}\text { Martensitic } \\
+\gamma^{\prime} \text { (large } \\
\text { amount) } \\
\text { Stress: } \\
\text { 2.49GPa }\end{array}$ \\
\hline $\begin{array}{l}\text { TMS-82+ } \\
\text { LT Pt-Al }\end{array}$ & $\begin{array}{l}\text { Mostly } \beta+ \\
\text { martensites } \\
+\gamma^{\prime} \text { (trace) } \\
\text { Stress: } \\
\text { 1.18GPa }\end{array}$ & $\begin{array}{l}\beta+\text { martensites } \\
\text { (significant) }+ \\
\gamma^{\prime} \text { (more trace) } \\
\text { Stress: } \\
\text { 1.78GPa }\end{array}$ & $\begin{array}{l}\text { Martensitic } \\
+\gamma^{\prime} \\
\text { (significant) } \\
\text { Stress: } \\
\text { 1.85GPa }\end{array}$ \\
\hline $\begin{array}{l}\text { CMSX-4 } \\
\text { LT Pt-Al }\end{array}$ & $\begin{array}{l}\text { All } \beta \\
\text { Stress: } \\
2.29 \mathrm{GPa}\end{array}$ & $\begin{array}{l}\beta+\text { martensites } \\
\text { (significant) } \\
\text { Stress: } \\
\text { 2.17GPa }\end{array}$ & $\begin{array}{l}\text { Martensitic } \\
+\gamma^{\prime} \\
\text { (significant) } \\
\text { Stress: } \\
\text { 2.09GPa }\end{array}$ \\
\hline $\begin{array}{l}\text { TMS-82+ Pt } \\
\text { diffusion }\end{array}$ & $\begin{array}{l}\text { Uniform } \\
\gamma \text { layer near } \\
\text { the interface } \\
\text { Stress: } \\
\text { 2.68GPa }\end{array}$ & $\begin{array}{l}\text { Uniform } \\
\gamma \text { layer near the } \\
\text { interface } \\
\text { Stress: } \\
\text { 2.84GPa }\end{array}$ & $\begin{array}{l}\text { Uniform } \\
\gamma \text { layer near } \\
\text { the interface } \\
\text { Stress: } \\
\text { 2.88GPa }\end{array}$ \\
\hline
\end{tabular}

From our previous study [18], the CMSX-4 LT Pt-Al and TMS$82+$ HT Pt-Al were the only specimens to have experienced a decline in TGO stress between 30 and $80 \mathrm{~h}$ of isothermal exposure, and in the case of CMSX-4 LT Pt-Al, the decline continued all the way to $100 \mathrm{~h}$ (Fig. 1). These two TBC were also previously determined to have an unexpected improvement in the interfacial adhesion between 30 and $100 \mathrm{~h}$ [18]. These observations suggest that the stress relaxation of the TGO by creep (i.e. rumpling of bond coat) can significantly influence the adhesion of TBC, and once again verified our previous proposed concept that the interfacial adhesion is a dynamic property. The TMS-82 LT Pt-Al, on the other hand, started out with relatively lower TGO stress having multiple phases after $30 \mathrm{~h}$ isothermal exposure, and continued to show an increasing trend in TGO stress until $100 \mathrm{~h}$ of isothermal exposure.

The SRR99 LT Pt-Al and the TMS-82+ HT Pt-Al specimens were particularly interesting due to their inherently different phase evolution and relatively poor interfacial adhesion when compared to other TBC. As shown in section 3.1 and 3.2, the SRR99 LT Pt$\mathrm{Al}$ specimens experienced a rapid transformation from the as coated $\beta$ to $\gamma^{\prime}$ phase by means of grain boundary diffusion, resulting in the formation of $\gamma^{\prime}$ phase at the grain boundary. This phenomenon is quite exclusive to the SRR99 LT Pt-Al specimens, as no other TBC prior to $200 \mathrm{~h}$ of thermal exposure duration, displayed $\beta$ to $\gamma^{\prime}$ phase transformation along the grain boundaries. The TMS-82+ HT Pt-Al specimen, on the other hand, was found to undergo a complete transformation from the as coated $\beta$ to a coarse martensitic structure after $30 \mathrm{~h}$ of isothermal exposure. In fact, this phenomenon was not observed on any other TBC studied in this work, regardless of the thermal exposure time. The TMS-82+ HT $\mathrm{Pt}-\mathrm{Al}$ specimen is also unique in that the grain size of its as coated $\beta$ phase appears to be much larger than those of the LT Pt-Al type. The larger grains can be explained by the fact that the aluminization processes of the TMS-82+ HT Pt-Al were carried out at a relatively high temperature of $1080^{\circ} \mathrm{C}$ in a low activity aluminum environment, and grain growth tends to be much rapid due to a higher diffusivity of atoms at high temperatures.

\section{$\underline{4.2 \text { Accelerated } \gamma^{\prime} \text { formation due to outward diffusion of } \mathrm{T} i}$}

It is known that the activation energy for chemical diffusion along the grain boundary, where vacancies due to defects and dislocation are present, is much lower than that required by lattice diffusion. Therefore, it makes sense that the grain boundaries are the preferred route for $\mathrm{Al}$ diffusion during high temperature oxidation. The TBC coated SRR99 specimen, together with all other TBC systems, should theoretically promote $\mathrm{Al}$ diffusion through the grain boundaries of the bond coat upon forming $\mathrm{Al}_{2} \mathrm{O}_{3}$ during thermal exposure. However, the question still remains as to why the formation of the $\gamma^{\prime}$ phase along the grain boundaries was exclusively observed on the SRR99 LT Pt-Al in early isothermal times. As previously confirmed by EDX, EPMA, and Thermo-Calc simulation [18], Ti and $\mathrm{Ni}$ contents have the tendency to segregate to $\mathrm{Al}$ depleted region, corresponding to the location of $\gamma^{\prime}$ phase. The SRR99 LT Pt-Al specimen, having a relatively higher Ti and $\mathrm{Ni}$ content (see Table I), was previously measured to have the fastest TGO growth kinetics and the $\gamma^{\prime}$ phase formation rate [18]. It is therefore believed that the inherently high $\mathrm{Ni}$ and $\mathrm{Ti}$ contents of the SRR99 alloy lead to a greater difference in chemical potential / free energy between the substrate and coating, which drives the $\mathrm{Al}$ diffusion process by ways of the grain boundary.

EPMA results in Figure 2 and 11 of the SRR99 LT Pt-Al and TMS$82+$ LT Pt-Al specimens, respectively, confirmed traces of Ti in the TGO layer, while Ti enriched $\gamma^{\prime}$ precipitates were present near the $\mathrm{TGO} /$ bond coat interface. The detrimental effect of $\mathrm{TiO}_{2}$ formation in degrading the adherence of the alumina scale is well documented [19-21]. The same degradation mechanism, however, does not seem to apply to the case of the TMS-82+ HT Pt-Al specimen. Despite having Ti containing $\gamma^{\prime}$ precipitates near the TGO/bond coat interface, no obvious Ti could be detected (see Figure 2) in the TGO scale from multiple EPMA maps taken at various locations along the interface. The concentration of Ti in the $\gamma^{\prime}$ precipitates of the TMS-82+ HT Pt-Al was considerably lower than that in the SRR99 LT Pt-Al specimen, which may be the reason behind the absence of $\mathrm{TiO}_{2}$. The degradation of the TMS-82+ HT Pt-Al specimen will be discussed in section 4.3 and 4.4. 
According to the results in section 3.4, $\mathrm{Cr}$ and Ta can stabilize the $\beta$ phase, delaying the formation of $\gamma^{\prime}$. Nonetheless, $\mathrm{Cr}$ seemed to be more effective than that of Ta. A comparison of the EPMA compositional mapping between the TMS-82+ LT Pt-Al and CMSX-4 LT Pt-Al specimens (Figure 11) revealed that $\mathrm{Cr}$ can effectively inhibit the diffusion of Ti content outward to the bond coat surface. In fact, the CMSX-4 LT Pt-Al, having relatively higher $\mathrm{Cr}$ content in the bulk alloy (see Table I), was shown to have relatively slower $\gamma^{\prime}$ formation despite having more bulk Ti content than the TMS-82+ LT Pt-Al specimen [18]. It should be noted that the stability of a certain phase may as well be influenced by other alloying elements in the bulk superalloy. Nonetheless, the results suggested that $\mathrm{Cr}$ plays a critical role in the prevention of early $\gamma^{\prime}$ formation.

\subsection{Martensitic transformation due to $\mathrm{Al}$ depletion}

Previous work by Smialek et al [22] indicated that the martensitic transformation temperature, $\mathrm{Ms}$, in $\beta-\mathrm{NiAl}$ alloy increases when $\mathrm{Al}$ depletion occurs as a result of oxidation and alloy/bond coat interdiffusion. They suggested that $\mathrm{Al}$ depletion with corresponding increase in the Ni content would decrease the ordering force of the stochiometric $\mathrm{NiAl}$, making the martensites as the dominant phase upon cooling. The previous EDX line profile study of the Pt-Al bond coats by $\mathrm{Wu}$ et al [17] showed that the Al content in the HT Pt-Al bond coat within a distance of $20 \mu \mathrm{m}$ from the TGO/bond coat interface is slightly lower ( $\sim 7$ at. $\%$ lower on average) than that in the LT Pt-Al. These findings suggest that the complete transformation to coarse martensite in the HT Pt-Al bond coat type is most likely due to its inherently low Al content, hence, having a higher Ms. It has been well known for decades that martensitic transformation does not undergo complete (ie. $100 \%$ ) transformation right below the Ms, but instead continues to increase in volume fraction with decreasing temperature [23] (i.e. increasing cooling).

According to the EBSD results shown earlier, significant degradation in the pattern quality was commonly found on specimens that underwent $\beta$ to martensitic transformation. This degradation tends to worsen with increasing thermal exposure, going from 30 to $100 \mathrm{~h}$. Qualitative and semi-quantitative assessments of local strain/deformation by utilizing both the changes in the EBSD pattern quality and grain misorientations have long been conducted in many previous studies [24-26]. Hence, it is believed that the progressive degradation in the EBSD pattern quality corresponds to the increasing severity of strain/deformation in the martensitic regions due to thermal exposure.

The High Temperature X-ray diffraction results in the work by Chen et al [27] indicated that the molar volume of the $\mathrm{L}_{0}$ martensite is approximately $2 \%$ smaller than that of the $\beta$, causing a transformation strain of about $-0.7 \%$ during cooling. This volume shrinkage due to martensitic transformation does generate additional stress during thermal cycling in the bond coat, and thus, can further increase rumpling growth [28]. It should be pointed out that the martensitic transformation in our specimens generated strain for the most part, as the experiment involved only isothermal exposure with a single cool-down process. EBSD results of 100 $\mathrm{h}$ isothermally exposed specimens revealed that the degradation of the martensites patterns tend to be the most severe when large $\gamma^{\prime}$ precipitates were formed as neighboring grains (see Figure 8). Based on this observation, it is proposed that the adjacent $\gamma^{\prime}$ grains, along with the TGO scale, may impede the contraction of martensites during cooling by imposing a tensile strain. This force exerted on the martensites is likely to be proportional to the size of $\gamma^{\prime}$ precipitates formed in the surroundings. Hence, TMS- $82+$ HT Pt$\mathrm{Al}$, having the most $\gamma^{\prime}$ formation $100 \mathrm{~h}$ into isothermal exposure, was shown to have the most severely degraded EBSD map. On the other hand, the CMSX-4 LT Pt-Al specimen with significantly less $\gamma^{\prime}$ formation than the TMS-82+ LT PT-Al after $100 \mathrm{~h}$ of isothermal exposure, had noticeably less degradation in its EBSD map. Note that the amount of $\gamma^{\prime}$ precipitates formation near the TGO/bond coat interface was thoroughly quantified on these TBC systems in the previous work [18], and used as reference for comparison here.

\subsection{Thermomechanical misfit induced by phase transformation}

It is proposed here that the co-existence of $\beta$, martensite, and $\gamma^{\prime}$ phases with inherently very different thermomechanical properties may induce a misfit stress in the TGO layer during thermal cycling, leading to an increase in rumpling amplitude of the TGO/bond coat interface. This concept can be best understood by studying the interfacial evolution of the TMS-82+ Pt-diffusion specimen. This specimen was shown to undergo a uniform $\mathrm{Al}$ depleted layer near the $\mathrm{TGO} /$ bond coat interface, with corresponding enrichment in $\mathrm{Cr}$. The segregation of $\mathrm{Ti}$ was also observed right beneath this $\mathrm{Al}-$ depleted and $\mathrm{Cr}$-enriched layer. This compositional distribution profile seems to be maintained between $30 \mathrm{~h}$ and $100 \mathrm{~h}$ of isothermal exposure, while the as-coated $\gamma^{\prime}+\gamma$ phase gradually transformed to a single $\gamma$ phase microstructure.

In a previous work [17], the TMS-82+ Pt-diffusion specimen was found to exhibit no rumpling behavior throughout its entire thermal cycling test, in comparison with other TBC systems. In addition, the TMS-82+ Pt diffusion specimen had some of the best interfacial adhesion among the TBC studied by the authors [18], despite having the largest TGO stress of the entire specimen set during thermal exposure. The reason behind these phenomena can be related to the uniform layer of $\gamma$ phase microstructure near the bond coat/TGO interface. Unlike the $\beta$ and martensitic transformation of $\mathrm{Pt}-\mathrm{Al}$ bond coat systems, there is no significant volume change associated with $\gamma^{\prime}$ to $\gamma$ transformation, and hence, does not produce rumpling growth [29]. Moreover, the Pt-diffusion systems do not have Ti segregation near the bond coat/TGO interface, and thus would not form $\mathrm{TiO}_{2}$ in the TGO layer. Contrary to the Pt-diffusion system, the TMS-82+ LT Pt-Al and TMS-82+ HT Pt-Al systems had relatively poor interfacial adhesion/spallation lifetime and continuous growth rumpling amplitude during thermal exposure [18].

\section{Conclusion}

The results of this work lead to the following conclusions:

- The early spallation of the $\beta$ bond coat systems is associated with two unique phase transformation phenomenon during thermal cycling: 1) $\gamma^{\prime}$ formation at the grain boundary and 2) complete martensitic transformation in early isothermal exposure.

- The progressive degradation in the EBSD pattern quality of the martensitic regions due to increasing $\gamma^{\prime}$ phases nearby has suggested that a misfit stress may be generated in the TGO layer due to the inherently different thermomechanical properties between different phases. 
- The experimental results have clarified the difference in the degradation mechanism between the SRR99 LT Pt-Al and TMS-82+ HT Pt-Al specimens. The early spallation occurred in the SRR99 LT Pt-Al most likely due to the precipitation of Ti concentrated $\gamma^{\prime}$ phase near the TGO/bond coat interface, and subsequently, led to the formation of the less adhesive $\mathrm{TiO}_{2}$ in the TGO layer. The early spallation of the TMS-82+ HT Pt-Al was mainly driven by the strain accumulation in the TGO as a result of the molar volume shrinkage associated with $\beta$ to $\gamma^{\prime}$ transformation during cooling

- Thermo-Calc and EPMA analysis indicated that $\mathrm{Cr}$ and $\mathrm{Ta}$, if given high enough amount, has the effect of preventing diffusion of $\mathrm{Ti}$ toward to the $\mathrm{TGO} /$ bond coat interface by stabilizing the $\beta$ and/or $\gamma$ phases.

- The results of this work has once again demonstrated that the TBC spallation lifetime bears close relationship with the variation of interfacial fracture toughness $\mathrm{G}_{\mathrm{c}}$ (critical strain energy release rate) and the driving force $G$ (strain energy release rate) [18].

\section{Acknowledgements}

Our appreciation goes to Ms. Hong Gao and Dr. Tadaharu Yokokawa of the National Institute for Materials Science (NIMS, Japan) for facilitating the analysis of EBSD and EPMA, respectively. In addition, we would like to extend our gratitude to Dr. Hiroshi Harada and Dr. Kyoko Kawagishi of NIMS, Japan, and Mr. Rodney Wing of Chromalloy - UK for the provision of research facilities and specimens.

\section{References}

[1] W.J. Bridely, R.A. Miller. Surf. Coat Technol, 43-44 (1990), pp. 446-457

[2] S. Stecura. Thin Solid Films, 73 (1980), pp. 481-489

[3] S. Stecura. Thin Solid Films, 182 (1989), pp. 121-139

[4] A.G. Evans, G.B. Crumley, R.E. Demaray. Oxid. Metals, 20 (1983), pp. 193-216

[5]G. Chang, W. Phucharoen, R.A. Miller. Surf. Coat Technol, 30 (1987), pp. 13-28

[6]A.G. Evans, M.Y. He, J.W. Hutchinson.Prog.Mater.Sci, 46 (2001), pp. 249-271

[7] M.Y. He, J.W. Hutchinson, A.G. Evans.Acta Mater, 50 (2002), pp. 1063-1073

[8] H.E. Evans, R.C. Lobb, Coor. Sci, 24 (1984), pp. 209-222

[9] H.E. Evans, G.P. Mitchell, R.C. Lobb, D.R.J. Owen. Proc. Roy. Soc, 440A (1993), pp. 1-22

[10] P. Deb, D.H. Boone, T.F. Manley. J. Vac. Sci. Technol A, 5 (1987), pp. 3366-3372

[11] R.C. Pennefather, D.H. Boone. Int. J. Press. Vess. Piping, 66 (1996), pp. 351-358

[12] E.P. Busso, Z.Q. Qian, M.P. Taylor, H.E. Evans. Acta Mater, 57 (2009), pp. 2349-2361

[13] A.M. Karlsson. Key Eng. Mater, 333 (2007), pp. 155-166

[14] U. Schulz, M. Menzebach, C. Leyen, Y.G. Yang. Surf. Coat Technol, 145-147 (2001),pp. 117-123

[15] B.A. Ping, J.A. Haynes, Y. Zhang. Surf. Coat Technol, 149 (2002), pp. 236-244

[16] R.T. Wu, K. Kawagishi, H. Harada, R.C. Reed. Acta Mater, 56 (2008), pp. 3622-3629
[17] R.T. Wu, X. Wang, A. Atkinson. Acta Mater, 58 (2010), pp. 5578-5585

[18] L.T. Wu, R.T. Wu, X. Zhao, P. Xiao. Mater.Sci. Eng. A, 594 (2014), pp. 193-202

[19] J.L. Smialek, G.H. Meier. Superalloys II (1987), pp. 293-326

[20] M. Levy, P. Farrell, F. Pettit. Corrosion-NACE, 42 (1986), pp. 708-717

[21] H.M. Tawancy, L.M. Al-Hadhrami. J. Eng. Gas. Turb. Power, 133 (2011), pp. 042101-6

[22] J.L. Smialek, R.F. Hehemann. Metall. Mater. Trans. A, 4 (1972), pp. 1571-1575

[23] U.D. Hangen, G. Sauthoff. Intermetallics, 7 (1999), pp. 501510

[24] A.J. Wilkinson, D.J. Dingley. Acta Metal. Mater, 39 (1991), pp. 3047-3055

[25] E.M. Lehockey, Y. Lin, O.E. Lepik. EBSD in Materials Science (2000), pp. 247-264

[26] M. Kamaya, A.J. Wilkinson, J.M. Titchmarsh. Nucl. Eng. Des, 235 (2005), pp. 713-725

[27] M.W. Chen, M.L. Glynn, R.T. Ott, T.C. Hufnagel, K.J. Hemker. Acta Mater, 51 (2003), pp. 4279-4294

[28] D.S. Balint, J. W. Hutchinson. J. Mechan. Phys. Solids, 53 (2005), pp. 949-973

[29] V.K. Tolpygo, D.R. Clarke. Acta Mater, 52 (2004), pp. 51155127 